\title{
Association of rs3746444 in MiRNA-499 and rs3787016 in Long Non-coding RNAs POLR2E with Prostate Cancer: an updated meta-analysis and systematic review
}

\section{Xuebin Liu}

Third Affiliated Hospital of Guangzhou Medical College

Yan Liu

Third Affiliated Hospital of Guangzhou Medical College

\section{Zhaozhang Wang}

Third Affiliated Hospital of Guangzhou Medical College

\section{Yuwu Li}

The People's Hospital of Gaozhou

\section{Yubin Li}

Third Affiliated Hospital of Guangzhou Medical College

\section{Zihao Zou}

Third Affiliated Hospital of Guangzhou Medical College

\section{Jianfeng Zhong}

Third Affiliated Hospital of Guangzhou Medical College

\section{Nan Deng}

Third Affiliated Hospital of Guangzhou Medical College

\section{Gaorui Zhou}

Third Affiliated Hospital of Guangzhou Medical College

Ping Liu ( $\nabla$ pingliu@gzhmu.edu.cn )

Third Affiliated Hospital of Guangzhou Medical College https://orcid.org/0000-0001-9566-6953

\section{Research}

Keywords: Meta-analysis, Prostate Cancer, rs3746444, rs3787016, MiRNA-499, LncRNA POLR2E

Posted Date: August 26th, 2020

DOI: https://doi.org/10.21203/rs.3.rs-64374/v1

License: (9) This work is licensed under a Creative Commons Attribution 4.0 International License. 
Page $2 / 20$ 


\section{Abstract \\ Background}

It has been proved that a significant proportion of prostate cancer diagnoses may be associated with a strong hereditary component. Micro-RNAs and Long Non-coding RNAs are a group of a noncoding small molecule, which play critical roles in signalling pathways, metabolism, apoptosis and cancer development. Exercising a meta-analysis to examine the relationship between rs3746444, rs3787016 and prostate cancer $(\mathrm{PCa})$ risk was the main objective of our study.

\section{Results}

10 case-control studies were included, while 6 on rs3787016 and 4 on rs3746444. On the whole, the genotypes carrying the $T$ allele, in which were verified an increased risk between rs3787016 and PCa risk.( T vs C: odds ratio(OR) $=1.802,95 \% \mathrm{Cl} 1.015-3.198, \mathrm{P}$ value of heterogeneity $\left(\mathrm{P}^{\mathrm{H}}\right)=0.00 \%$; $\mathrm{CT}$ vs $\mathrm{CC}$ : $\mathrm{OR}=$ $1.179,95 \% \mathrm{Cl} 1.091-1.275, \mathrm{P}^{\mathrm{H}}=0.41$; TT vs CC: .OR $=1.418,95 \% \mathrm{Cl} 1.229-1.636, \mathrm{P}^{\mathrm{H}}=0.961 ; \mathrm{TT}+\mathrm{CT}$ vs CC: $O R=1.216,95 \%$ Cl 1.129-1.310, $\mathrm{P}^{\mathrm{H}}=0.408$; $\mathrm{TT}$ vs $\mathrm{CT}+\mathrm{CC}: \mathrm{OR}=1.328,95 \% \mathrm{Cl} 1.159-1.521, \mathrm{P}^{\mathrm{H}}=$ 0.987). A vital relevance was performed by this meta-analysis in three models between rs 3746444 and $P C a$ risk, in which a tendency of increased PCa risk could be found ( $C$ vs $T: O R=1.197,95 \% \mathrm{Cl} 1.035-$ $1.384, \mathrm{P}^{\mathrm{H}}=0.837 ; \mathrm{CC}$ vs TT: $\mathrm{OR}=1.137,95 \% \mathrm{Cl} 0.813-1.590, \mathrm{P}^{\mathrm{H}}=0.392 ; \mathrm{CC}+\mathrm{CT}$ vs TT: $\mathrm{OR}=1.426,95 \%$ $\mathrm{Cl} 1.166-1.743, \mathrm{P}^{\mathrm{H}}=0.406$.).

\section{Conclusion}

Our findings proposed that rs3746444 in MiRNA-499 and rs3787016 in Long Non-coding RNAs POLR2E polymorphisms increased the risk of developing PCa. Further functional studies are warranted to reveal the role of the polymorphism in carcinogenesis.

\section{Background}

For being the second most frequent cancer diagnosis made in men, prostate cancer hits the list leading cause of death around the world at number five [1,2]. Giving no warning signals at earlier period, prostate cancer often performed as tardy progress that may only stand in need of active monitoring. Nevertheless, the clinical conformity case was often identified at or toward an end or late period or stage of development with poor prognosis. With the constant upgrading of potential diagnostic biomarkers of prostate cancer and the technological innovations of surgical techniques, diagnosed in the early stage, prostate cancer can be cured by radical resection, local radiotherapy or ablation. When it turned to advanced diseases, the survival rate still has declined rapidly when bone metastasis and lymphatic metastasis occurred, although endocrine therapy and chemotherapy have made considerable progress [3]. As the subject of quite a few studies, compared to other common tumor, the development or morbid 
condition of prostate cancer and further study is needed. Including old aging, ethnicity, individual heredity factors and family history $[2,4]$ both were the generally-accepted risk factors of prostate cancer. Thus, diagnosing the individuals in danger of hereditary prostate cancer and potential other factors which contribute to the early detection and handle the development of PCa was urgent for us [5]. So far, when it turned to the populations of European and Non-European lineage, in which more than 177 singlenucleotide polymorphisms (SNPs) have been corroborated affiliated with PCa by a great number of genome-wide association studies. Numerous SNPs have been apparently investigated and verified to increase risk facilitating to the advancement of PCa [2]. Likewise, advancement of PCa maybe was caused by both various expressions of multitudinous oncogenes and cancer suppressors in which MicroRNAs (MiRNAs) or Long Non-coding RNAs (LncRNAs) play important parts [6, 7]. To verified genetic decisive factors of prostate cancer risk, more than 36 genome-wide association studies (GWAS) on PCa have reported proximately 582 exclusive prostate cancer risk SNPs, which was based on the NHGRI-EBI catalogue of published GWASs. First and foremost, many of these reported SNPs have subsequently been certified in forcefulness case-control studies $[8,9]$.

Located at 16p13 encodes a subunit of RNA polymerase II, the POLR2E LncRNA gene was in charge of producing messenger RNA (mRNA) [10,11]. Rare studies have identified the impact of rs3787016 polymorphism on the risk of PCa [12-15], which was the same as esophageal squamous cell carcinoma (ESCC) [16], while the findings were inconsistent and conflicting.

Found at 27q11.11 chromosome [17], the MiRNA-499 rs3746444 gene polymorphism have been identified by some studies, in which a single nucleotide variation can create a mismatch in the stem area of the MiRNA-499 precursor as well as change the secondary construction of MiRNA.

Notwithstanding, hardly any studies evaluated the association between these SNPs with the risk of PCa as well as quite a few investigations have been reported the functional significant effects of nucleotide changes in genes encoding of LncRNA POLR2E and MiRNA-499[6, 7]. While in the present investigation, we aimed to estimate the association between LncRNA POLR2E and MiRNA-499 gene polymorphisms with the risk of PCa patients [12-15, 18-21], owing to the inconsistencies regarding the impact of LncRNA or MiRNA gene polymorphisms on prostate cancer affectability.

\section{Results}

\section{Literature Search}

On the basis of inclusion and exclusion standard, 8 articles were picked up. One multi-center article which included as 3 independent studies enlisted population from the same regions. Consequently, 6 casecontrols (5650 cases and 6325 controls) and 4 case-control (833 cases and 869 controls) separately were collected to assess the association of rs3787016 and rs3746444 with PCa risk [12-15, 18-21] (Fig. 1).

\section{Study Characteristics}




\section{Association between rs3746444 and risk of PCa}

To research on the association of rs3746444 and PCa, four included studies were assessed. Fixed-effects model was used recognizing no significant heterogeneity in homozygote model of rs3746444, dominant model of rs 3746444 and allele model of rs3746444, while random-effects model used in heterozygote model of rs3746444, recessive model of rs3746444.

A significant association was expressed in three models between rs3746444 and PCa risk, in which a trend of increased risk could be detected ( $\mathrm{C}$ vs $\mathrm{T}$ : $\mathrm{OR}=1.197,95 \% \mathrm{Cl} 1.035-1.384, \mathrm{P}^{\mathrm{H}}=0.837$; $\mathrm{CT}$ vs TT: $\mathrm{OR}=1.536,95 \% \mathrm{Cl} 1.108-2.129, \mathrm{P}^{\mathrm{H}}=0.087 ; \mathrm{CC}$ vs TT: $\mathrm{OR}=1.137,95 \% \mathrm{Cl} 0.813-1.590, \mathrm{P}^{\mathrm{H}}=0.392 ; \mathrm{CC}+$ CT vs TT: $O R=1.426,95 \% \mathrm{Cl} 1.166-1.743, \mathrm{P}^{\mathrm{H}}=0.406 ; \mathrm{CC}$ vs $\mathrm{CT}+\mathrm{TT}: \mathrm{OR}=0.922,95 \% \mathrm{Cl} 0.540-1.574$, $\left.\mathrm{P}^{\mathrm{H}}=0.025\right)$ (Table 1).

\section{Association between rs3787016 and risk of PCa}

For LncRNA POIR2E polymorphism, a noticeable correlation was observed between the rs3787016 C > T polymorphism and $\mathrm{PCa}$ risk in allele comparison (random effects $\mathrm{OR}=1.802,95 \% \mathrm{Cl}=1.015-3.198, \mathrm{P}^{\mathrm{H}}$ $=0.00 \%$ ) while we investigated the relationship between LncRNA POIR2E rs3787016 polymorphism and PCa risk.

No significant heterogeneity was identified by Q-test and F statistic in any genetic models except Allele model. And then, the fixed-effects model was applied in other four models. Generally. Fulfilled in genotypes carrying the $T$ allele, an increased risk was apparently detected in the following genotype models(T vs C: $\mathrm{OR}=1.802,95 \% \mathrm{Cl} 1.015-3.198, \mathrm{P}^{\mathrm{H}}=0.00 \% ; \mathrm{CT}$ vs $\mathrm{CC}: \mathrm{OR}=1.179,95 \% \mathrm{Cl} 1.091-1.275$, $\mathrm{P}^{\mathrm{H}}=0.41$; TT vs CC: $. \mathrm{OR}=1.418,95 \% \mathrm{Cl} 1.229-1.636, \mathrm{P}^{\mathrm{H}}=0.961 ; \mathrm{TT}+\mathrm{CT}$ vs CC: $\mathrm{OR}=1.216,95 \% \mathrm{Cl}$ 1.129-1.310, $\mathrm{P}^{\mathrm{H}}=0.408$; TT vs CT + CC: OR $=1.328,95 \% \mathrm{Cl} 1.159-1.521, \mathrm{P}^{\mathrm{H}}=0.987$ ) (Fig. 3).

Additionally, subgroup analysis was conducted to check out the effects of ethnicity, source of controls, country, genotype methods (Fig. 3 and Table 1).

\section{Subgroup analysis}

Subgroup analysis was conducted to determine the heterogeneity of sources by assessing the effects of ethnicity, source of controls, country, genotype methods, HWE (only in rs3746444). In the allelic model(T vs C) of rs3787016, performed in fixed effect model, ethnicity (heterogeneity between groups: $\mathrm{P}^{\mathrm{G}}=0.000$ ), genotype methods $\left(P^{G}=0.000\right)$, and source of controls $\left(P^{G}=0.000\right)$ all suggested significant intergroup heterogeneity. In the heterozygote model[CT vs TT $\square$ of rs3746444, conducted in fixed effect model, including ethnicity $\left(P^{G}=0.035\right)$, genotype methods $\left(P^{G}=0.035\right)$, and source of controls $\left(P^{G}=0.018\right)$ all suggested significant intergroup heterogeneity. In the recessive model $\square C C$ vs CT + TT $\square$ of rs3746444, conducted in fixed effect model, including ethnicity $\left(P^{G}=0.037\right)$, genotype methods $\left(P^{G}=0.037\right)$, and source of controls $\left(P^{G}=0.014\right)$ all suggested significant intergroup heterogeneity. 


\section{Sensitivity analysis}

In order to assess the stability of the pooled ORs with the effect of the individual studies, we conducted a sensitivity analysis. With removal of individual study result from the analysis for rs3787016 or rs3746444, we found that the studies of Cao DL et al and JHH et al were major sources of heterogeneity in allele model of rs3787016 (from 36.8-98.5\%), while the study of Nouri et al was a major source of heterogeneity in recessive model of rs3746444 (from 0.00-67.9\%) (Fig. 4).

\section{Meta-regression}

For PCa risk, we detected a substantial heterogeneity in heterozygote model of rs3746444, recessive model of rs3746444 and allele model of rs3787016. The meta-regression analysis we conducted was designed to verify the heterogeneity of sources and the results were shown in the supplemental material (Figure S1, Figure S2 and Figure S3). Nevertheless, the results cannot detect the source of the heterogeneity in heterozygote model of rs3746444,recessive model of rs3746444. But we found that ethnicity was a major source of heterogeneity in allele model of rs3787016 $(p=0.001)$.

\section{Publication bias}

We used Begg's test and Egger's test to assess publication bias. No evidence of publication bias was shown in all genotype models of rs3787016 and rs3746444 (P-value not is shown) (Fig. 5).

\section{Discussion}

Involved in process of carcinogenesis, the studies of polymorphism genes have attracted more and more attention, making genetic susceptibility to malignant tumors a hot subject in the international academy. Through imperfect pairing with target mRNAs of protein-coding genes, evidence that MiRNAs played an important role in various crucial biological processes has been showed by earlier researches [22, 23]. Noncoding RNA includes highly plentiful and functionally important RNAs, such as MicroRNAs and long noncoding RNAs. Changes of MicroRNAs or non-coding RNAs had a profound impact on the tumorigenesis of prostate cancer $[24,25]$. SNPs in MicroRNAs and non-coding RNAs regions may involve in these processes by way of changing their maturation and expression as oncogenes. Acting as the precursors of small non-coding RNAs, LncRNAs can produce MicroRNAs as well as endogenous small interfering RNA or served as a microRNA sponge to inhibit microRNA activity [26, 27]. Meanwhile, several LncRNA also play vital roles, activating or suppressing oncogenes [28, 29].

Rs3787016, localizes to the fourth intron of RNA polymerase II polypeptide E (POLR2E) 16 gene, has been investigated by several researchers on its association with cancer risk [16,30-37].The most important function of LncRNAs is involvement in the transcriptional or posttranscriptional regulation of gene expression[38]. Abnormal expressions of these RNAs facilitate tumor-cell proliferation, invasion and survival in cancer development and progression [39-41]. There is a tremendous amount of developmental biological mechanisms of LncRNAs function in cancer that is unclaimed by most of 
existing theories. To sum up, there was an increased risk in genotypes carrying the $T$ allele. But we found an obvious heterogeneity $\left(\mathrm{I}^{2}=98.5 \%, \mathrm{P}^{\mathrm{H}}=0.000\right)$ in terms of allele model of rs 3787016 . In order to ascertain the heterogeneity of sources, we conducted subgroup analyses and the results detect that including ethnicity $\left(p^{G}=0.000\right)$, genotype methods $\left(p^{G}=0.000\right)$ and source of controls $\left(p^{G}=0.000\right)$ both were the sources of the heterogeneity. Meanwhile, we also found that the study of Cao DL et al and the study of $\mathrm{JHH}$ et al were major sources of heterogeneity in allele model of rs3787016 (from 36.8-98.5\%) by performing a sensitivity analysis, we conducted a meta-regression analysis and the results were shown that ethnicity was a major source of heterogeneity in allele model of rs3787016. Lacking in amplitude or quantity, as regards sources of controls, more studies in different populations should be involved in identifying convincible effects. Particularly we find that there is still a lack of research on the east asian race. Before these reported findings will contribute to clinical decision-making, additional studies with a larger sample size and in different ethnic populations are needed to confirm or further reinforce our present findings.

MicroRNA-499 rs3746444 has been proved to be significantly associated with increased risk of cancer of the respiratory system, digestive system, urinary system[and gynecological system[42-53].Existing studies have been verified that the MiRNA-499(rs3746444 T >C) gene polymorphism can control the expression level of SOX gene. Due to the up-regulation of SOX6 gene, the anti-apoptosis function of MiRNA-499(rs3746444 T >C) can be reversed [54]. Deregulation of SOX gene leads to activation Wnt/ $\beta$ catenin signaling pathway, and the pathway correlated with cancerogenesis. With the changes of SOX gene expression, the rs 3746444 variants might play a critical role in the tumor formation. There is an increased risk was identified in genotypes most carrying the $\mathrm{C}$ allele. We also found obvious heterogeneity in terms of heterozygote model of rs $3746444\left(\mathrm{I}^{2}=54.4 \%, \mathrm{P}^{\mathrm{H}}=0.087\right)$ and recessive model of rs3746444 $\left(\mathrm{I}^{2}=67.9 \%, \mathrm{P}^{\mathrm{H}}=0.025\right)$. To ascertain the heterogeneity of sources, we conducted subgroup analyses and the results were shown that ethnicity, country and genotype methods were major sources of heterogeneity.

When we conducted the sensitivity analysis of the rs3787016, we found that significant decreases of pooled heterogeneity after excluding the study of Cao DL et al and $\mathrm{JHH}$ et al. This result needed to be further verified because there were only 5 studies included and the lack of statements for sources of controls. At the same time, we found that the study of Nouri et al may be the main source of heterogeneity in rs3746444). The result of Begg's test of all models of the rs3787016 and rs3746444 showed no publication bias. After all, this meta-analysis existed still had some limitations. Firstly, funnel plots for publication bias which we have detected in rs3746444 polymorphism might exist while we didn't detect owing to quantitative restrictions of studies. Secondly, two studies of MiRNA-499 rs3746444 did not meet HWE criteria. Thirdly, the detailed information (such as age, sex, menstrual history, life style and environmental factors) was not considered so that our unadjusted estimates should be confirmed by further studies. Still, our results were supported by existing literature, while further well-designed large studies are warranted to clarify the possible role of these polymorphisms in more details. 
Nevertheless, supported by the existing literature, our investigation is necessary to take in more welldesigned large-scale studies to clarify the possible role of these polymorphisms at full length.

\section{Conclusion}

In conclusion, our findings proposed that rs3746444 in MiRNA-499 and rs3787016 in Long Non-coding RNAs POLR2E polymorphisms increased the risk of developing PCa. Further functional studies are warranted to reveal the role of the polymorphism in carcinogenesis.

\section{Methods}

\section{Search Strategy}

Aiming to systematically retrieve studies describing the relationship between rs3787016, rs3746444 and prostate cancer risk, we searched PubMed and EMBASE on March 1, 2020, and conducted the literature search as well as references list of included studies and reviews once more on Jun 4, 2020, which guaranteed the data of our research was current and available. The search attached importance to following subject terms and keywords: rs3787016, rs3746444, prostate cancer, of which detailed strategies are provided in the supplemental material.

\section{Study Selection}

As for literature eligibility, two investigators accomplished the assessments separately, while contradictory conclusions were resolved in terms of debate and unanimity. Inclusion criteria were as follows: (a) studies that was digging at the association of LncRNA POLR2E/miR-499 and PCa in full-text; (b) utilizing an irrelevant case-control design; (c) study published in English; (d) data provided make conducting an OR with $95 \% \mathrm{Cl}$ possible; (e) sufficient counting of genotypes or allele frequencies. Exclusion criteria: (1) comment, review, meta-analysis, and editorial; (2) Only the largest sample was included when it turned to multiple publications from the same population/area (Figure 6).

\section{Data Extraction}

The following information was draw out and inducted to specially designed forms from the included studies by two investigators separately : first author's last name, year of publications, country of origin, ethnicity, study-design (sources of controls), sample size in cases and controls, the number of cases and controls with variant allele and wild type, genotyping methods and hardy weinberg equilibrium (HWE) of the studies respectively. For each publication, all data complying with the selection criteria were reviewed and extracted independently by two of the investigators. If dissent existed, the authors rechecked the 
original data and held a discussion to reach a consensus. When it still existed, discrepancies would be adjudicated by a third reviewer until the consensus was achieved on every item (Table 2).

\section{Statistical Analysis}

Based on the PRISMA checklists [55], the meta-analysis which we performed rest on the guidelines. Calculated to assess intensity correlations between rs3787016/ rs3746444 polymorphism and PCa risk, the pooled ORs with 95\% Cls were performed for allelic comparison (LncRNA POLR2E: T vs C, miR-499: C vs T), heterozygote model (LncRNA POLR2E: CT vs CC, miR-499: CT vs TT), homozygote model (LncRNA POLR2E: TT vs CC, miR-499: CC vs TT), dominant model (LncRNA POLR2E: CT+TT vs CC, miR-499: CC+CT vs TT), recessive model (LncRNA POLR2E: TT vs CC+CT, miR-499: CC vs CT+TT), respectively. Ztest was used to determine the pooled $\mathrm{OR}$ and $95 \% \mathrm{Cl}$, and $\mathrm{P}<0.05$ was regarded as statistically significant. Statistical heterogeneity among studies was estimated by the Q statistic (significance level of $\mathrm{P}<0.05$ ) and $\mathrm{I}^{2}$ statistic (greater than $50 \%$ as evidence of significant inconsistency). The $Q$ test and $\mathrm{I}^{2}$ statistic were used for testing variation in accordance with heterogeneity. Random effects model[56] would be used if $\mathrm{P}^{\mathrm{H}}$ was no more than $0.05\left(\mathrm{P}^{\mathrm{H}}<0.05\right)$, and when $\mathrm{P}^{\mathrm{H}}$ was $>0.05$, fixed effects model was used $^{21}$. Sensitivity analysis was also tested by removing one study at a time, to evaluate the effect of removal and effect of size of each study on the homogeneity of the whole. Furthermore, subgroup analyses were stratified by ethnicity, source of controls, country, genotype methods, HWE (only in rs3746444). Publication bias was conducted by Begg's funnel plots and further assessed by the Egger's regression test $[57,58]$. When an asymmetric plot was shown or Begg 's test was $\mathrm{P}<0.05$, we considered it as a significant publication bias. Besides, Hardy-Weinberg equilibrium (HWE) was implemented to identify the effective records in our study [59]. All the statistical analyses and graphics above were available to run under Stata 12.0 software (Stata Corp LP 4905, Lakeway Drive College Station, TX 77845 USA). A two tailed $\mathrm{P}<0.05$ was regarded as significant, except for specified conditions, which a certain Pvalue was declared, The Newcastle-Ottawa Quality Assessment Scale (NOS)[60] was used to evaluate the quality of include studies (Figure 7).

\section{Abbreviations}

$\mathrm{Cl}$, confidence interval; $\mathrm{HB}$, hospital-based; HWE, Hardy-Weinberg equilibrium; LncRNA, Long Non-coding RNA; MiRNA, Micro-RNA; OR, odds ratio; PB, population-based; PCa, Prostate Cancer; $\mathrm{P}^{\mathrm{H}}, \mathrm{P}$ value of heterogeneity; $\mathrm{P}^{\mathrm{G}}$, heterogeneity between groups; Unknown, not provided in the original reference.

\section{Declarations}

\section{Acknowledgments}


We acknowledge that Third Affiliated Hospital of Guangzhou Medical University for supporting the work of our study.

\section{Authors' Contributions}

Xuebin Liu and Ping Liu designed the study. Yan Liu, Zhaozhang Wang, and Gaorui Zhou completed the literature eligibility assessment, extraction, and analysis of data. Zihao Zou, Jianfeng Zhong and Nan Deng reviewed the results. Xuebin Liu and Yuwu Li wrote the report. All authors participated in the discussion and modification of the text. All authors approved the final version of the paper.

\section{Funding}

Not applicable.

\section{Availability of data and materials}

The datasets used and analysed during the current study are available from the corresponding author on reasonable request.

\section{Ethics approval and consent to participate}

Not applicable.

\section{Consent for publication}

Not applicable.

\section{Conflicts of Interest}

The authors declare that they have no conflicts of interest.

\section{References}


1. Ferlay J, Colombet M, Soerjomataram I, Mathers C, Parkin DM, Piñeros M, Znaor A, Bray F. Estimating the global cancer incidence and mortality in 2018: GLOBOCAN sources and methods. INT J CANCER. 2019; 144(8):1941-1953.

2. Rawla P. Epidemiology of Prostate Cancer. World Journal of Oncology. 2019; 10(2):63-89.

3. N. Mottet Chair RCNV, E. Briers Patient Representative PCVM: EAU - EANM - ESTRO - ESUR - SIOG Guidelines on Prostate Cancer. In.: Eur Association Urol; 2019.

4. Zhen JT, Syed J, Nguyen KA, Leapman MS, Agarwal N, Brierley K, Llor X, Hofstatter E, Shuch B. Genetic testing for hereditary prostate cancer: Current status and limitations. CANCER-AM CANCER SOC. 2018; 124(15):3105-3117.

5. Huang S, Cui H, Lou Z, Wang X, Chen L, Xie Z, Hehir M, Yao X, Ren Y, Cen D et al. Association of rs3787016 in Long Non-coding RNAs POLR2E and rs2910164 in MiRNA-146a with Prostate Cancer: A Systematic Review and Meta-analysis. IRAN J PUBLIC HEALTH. 2018; 47(5):623-632.

6. Aghdam SG, Ebrazeh M, Hemmatzadeh M, Seyfizadeh N, Shabgah AG, Azizi G, Ebrahimi N, Babaie F, Mohammadi $\mathrm{H}$. The role of microRNAs in prostate cancer migration, invasion, and metastasis. J CELL PHYSIOL. 2018; 234(7):9927-9942.

7. Mitobe Y, Takayama KI, Horie-Inoue K, Inoue S. Prostate cancer-associated IncRNAs. CANCER LETT. 2018; 418:159-166.

8. Buniello A, MacArthur JAL, Cerezo M, Harris LW, Hayhurst J, Malangone C, McMahon A, Morales J, Mountjoy E, Sollis E et al. The NHGRI-EBI GWAS Catalog of published genome-wide association studies, targeted arrays and summary statistics 2019. NUCLEIC ACIDS RES. 2019; 47(D1):D1005D1012.

9. Benafif S, Kote-Jarai Z, Eeles RA. A Review of Prostate Cancer Genome-Wide Association Studies (GWAS). CANCER EPIDEM BIOMAR. 2018; 27(8):845-857.

10. Hsieh C, Oakley-Girvan I, Balise RR, Halpern J, Gallagher RP, Wu AH, Kolonel LN, O'Brien LE, Lin IG, Van Den Berg DJ et al. A Genome Screen of Families with Multiple Cases of Prostate Cancer: Evidence of Genetic Heterogeneity. The American Journal of Human Genetics. 2001; 69(1):148-158.

11. Kar SP, Beesley J, Amin Al Olama A, Michailidou K, Tyrer J, Kote-Jarai Z, Lawrenson K, Lindstrom S, Ramus SJ, Thompson DJ et al. Genome-Wide Meta-Analyses of Breast, Ovarian, and Prostate Cancer Association Studies Identify Multiple New Susceptibility Loci Shared by at Least Two Cancer Types. CANCER DISCOV. 2016; 6(9):1052-1067.

12. Cao D, Gu C, Zhu Y, Dai B, Zhang H, Shi G, Shen Y, Zhu Y, Ma C, Xiao W et al. Polymorphisms at long non-coding RNAs and prostate cancer risk in an eastern Chinese population. PROSTATE CANCER $P$ D. $2014 ; 17(4): 315-319$.

13. Nikolić ZZ, Brajušković GN, Pavićević DLS, Kojić AS, Vukotić VD, Tomović SM, Cerović SJ, Filipović V, Mišljenović D, Romac SP. Assessment of possible association between rs3787016 and prostate cancer risk in Serbian population. INT J CLIN EXP MED. 2013; 6(1):57.

14. Jin G, Sun J, Isaacs SD, Wiley KE, Kim S, Chu LW, Zhang Z, Zhao H, Zheng SL, Isaacs WB et al. Human polymorphisms at long non-coding RNAs (IncRNAs) and association with prostate cancer 
risk. CARCINOGENESIS. 2011; 32(11):1655-1659.

15. Sattarifard H, Hashemi M, Hassanzarei S, Basiri A, Narouie B, Ghavami S. Long non-coding RNA POLR2E gene polymorphisms increased the risk of prostate cancer in a sample of the Iranian population. Nucleotides and Nucleic Acids. 2019; 38(1):1-11.

16. Kang M, Sang Y, Gu H, Zheng L, Wang L, Liu C, Shi Y, Shao A, Ding G, Chen S et al. Long noncoding RNAs POLR2E rs3787016 C/T and HULC rs7763881 A/C polymorphisms are associated with decreased risk of esophageal cancer. Tumour Biol. 2015; 36(8):6401-6408.

17. Siddiq A, Couch FJ, Chen GK, Lindström S, Eccles D, Millikan RC, Michailidou K, Stram DO, Beckmann $\mathrm{L}$, Rhie SK et al. A meta-analysis of genome-wide association studies of breast cancer identifies two novel susceptibility loci at 6q14 and 20q11. HUM MOL GENET. 2012; 21(24):5373-5384.

18. George GP, Gangwar R, Mandal RK, Sankhwar SN, Mittal RD. Genetic variation in microRNA genes and prostate cancer risk in North Indian population. MOL BIOL REP. 2011; 38(3):1609-1615.

19. Hashemi M, Moradi N, Ziaee SA, Narouie B, Soltani MH, Rezaei M, Shahkar G, Taheri M. Association between single nucleotide polymorphism in miR-499, miR-196a2, miR-146a and miR-149 and prostate cancer risk in a sample of Iranian population. J ADV RES. 2016; 7(3):491-498.

20. Nikolić Z, Savić Pavićević D, Vučić N, Cidilko S, Filipović N, Cerović S, Vukotić V, Romac S, Brajušković $\mathrm{G}$. Assessment of association between genetic variants in microRNA genes hsa-miR-499, hsa-miR$196 a 2$ and hsa-miR-27a and prostate cancer risk in Serbian population. EXP MOL PATHOL. 2015; 99(1):145-150.

21. Nouri R, Ghorbian S. Association of single nucleotide polymorphism in hsa-miR-499 and hsa-miR196a2 with the risk of prostate cancer. INT UROL NEPHROL. 2019; 51(5):811-816.

22. Bartel DP, Chen CZ. Micromanagers of gene expression: the potentially widespread influence of metazoan microRNAs. NAT REV GENET. 2004; 5(5):396-400.

23. Chu R, Mo G, Duan Z, Huang M, Chang J, Li X, Liu P. miRNAs affect the development of hepatocellular carcinoma via dysregulation of their biogenesis and expression. CELL COMMUN SIGNAL. 2014; 12:45.

24. Kojima S, Goto Y, Naya Y. The roles of microRNAs in the progression of castration-resistant prostate cancer. J HUM GENET. 2017; 62(1):25-31.

25. Bartel DP. MicroRNAs: target recognition and regulatory functions. CELL. 2009; 136(2):215-233.

26. Gutschner T, Diederichs S. The hallmarks of cancer: a long non-coding RNA point of view. RNA BIOL. 2012; 9(6):703-719.

27. Wang J, Liu X, Wu H, Ni P, Gu Z, Qiao Y, Chen N, Sun F, Fan Q. CREB up-regulates long non-coding RNA, HULC expression through interaction with microRNA-372 in liver cancer. NUCLEIC ACIDS RES. 2010; 38(16):5366-5383.

28. Sun T, Ye H, Wu CL, Lee GS, Kantoff PW. Emerging players in prostate cancer: long non-coding RNAs. Am J Clin Exp Urol. 2014; 2(4):294-299. 
29. Dai X, Liang Z, Liu L, Guo K, Xu S, Wang H. Silencing of MALAT1 inhibits migration and invasion by sponging miR13p in prostate cancer cells. MOL MED REP. 2019; 20(4):3499-3508.

30. Xu T, Hu XX, Liu XX, Wang HJ, Lin K, Pan YQ, Sun HL, Peng HX, Chen XX, Wang SK et al. Association between SNPs in Long Non-coding RNAs and the Risk of Female Breast Cancer in a Chinese Population. J CANCER. 2017; 8(7):1162-1169.

31. Chen B, Jiao Y, Yaolong F, Li T, Liu Y, Wang M, Xiuli G, Feng X. The POLR2E rs3787016 polymorphism is strongly associated with the risk of female breast and cervical cancer. PATHOL RES PRACT. 2019; 215(5):1061-1065.

32. Chen B, Wang S, Ma G, Han J, Zhang J, Gu X, Feng X. The association of POLR2E rs3787016 polymorphism and cancer risk: a Chinese case-control study and meta-analysis. Biosci Rep. 2018; 38(6).

33. Huang S, Cui H, Lou Z, Wang X, Chen L, Xie Z, Hehir M, Yao X, Ren Y, Cen D et al. Association of rs3787016 in Long Non-coding RNAs POLR2E and rs2910164 in MiRNA-146a with Prostate Cancer: A Systematic Review and Meta-analysis. IRAN J PUBLIC HEALTH. 2018; 47(5):623-632.

34. Chu H, Chen Y, Yuan Q, Hua Q, Zhang X, Wang M, Tong N, Zhang W, Chen J, Zhang Z. The HOTAIR, PRNCR1 and POLR2E polymorphisms are associated with cancer risk: a meta-analysis. Oncotarget. 2017; 8(26):43271-43283.

35. Gong WJ, Peng JB, Yin JY, Li XP, Zheng W, Xiao L, Tan LM, Xiao D, Chen YX, Li X et al. Association between well-characterized lung cancer IncRNA polymorphisms and platinum-based chemotherapy toxicity in Chinese patients with lung cancer. ACTA PHARMACOL SIN. 2017; 38(4):581-590.

36. Chen B, Li J, Yi C, Jiao Y, Gu X, Feng X. Long non-coding RNA POLR2E rs3787016 is associated with the risk of papillary thyroid carcinoma in Chinese population. PATHOL RES PRACT. 2018; 214(7):1040-1044.

37. Deng Y, Zhou L, Li N, Wang M, Yao L, Dong S, Zhang M, Yang P, Hao Q, Wu Y et al. Impact of four IncRNA polymorphisms (rs2151280, rs7763881, rs1136410, and rs3787016) on glioma risk and prognosis: A case-control study. Mol Carcinog. 2019; 58(12):2218-2229.

38. Shields EJ, Petracovici AF, Bonasio R. IncRedibly versatile: biochemical and biological functions of long noncoding RNAs. BIOCHEM J. 2019; 476(7):1083-1104.

39. Kuo TC, Kung HJ, Shih JW. Signaling in and out: long-noncoding RNAs in tumor hypoxia. J BIOMED SCl. 2020; 27(1):59.

40. Kunej T, Obsteter J, Pogacar Z, Horvat S, Calin GA. The decalog of long non-coding RNA involvement in cancer diagnosis and monitoring. Crit Rev Clin Lab Sci. 2014; 51(6):344-357.

41. Sana J, Faltejskova P, Svoboda M, Slaby O. [Long non-coding RNAs and their relevance in cancer]. Klin Onkol. 2012; 25(4):246-254.

42. Yang XK, Li P, Zhang C, Leng RX, Li S, Liu J, Li BZ, Pan HF, Ye DQ. Association between IRAK1 rs3027898 and miRNA-499 rs3746444 polymorphisms and rheumatoid arthritis : A case control study and meta-analysis. Z RHEUMATOL. 2017; 76(7):622-629. 
43. Yan W, Gao X, Zhang S. Association of miR-196a2 rs11614913 and miR-499 rs3746444 polymorphisms with cancer risk: a meta-analysis. Oncotarget. 2017; 8(69):114344-114359.

44. Ghobadi F, Vaisi-Raygani A, Bahrehmand F, Tanhapour M, Kiani A, Rahimi Z, Pourmotabbed T. Genetic Variants of Pre-microRNAs A-499G(rs3746444) and T-196a2C(rs11614913) with Ulcerative Colitis (UC) and Investigated with Thiopurine-S-Methyltransferase (TPMT) Activity. CLIN LAB. 2017; 63(10):1683-1690.

45. Zhang H, Zhang Y, Yan W, Wang W, Zhao X, Ma X, Gao X, Zhang S. Association between three functional microRNA polymorphisms (miR-499 rs3746444, miR-196a rs11614913 and miR-146a rs2910164) and breast cancer risk: a meta-analysis. Oncotarget. 2017; 8(1):393-407.

46. Tang W, Wang Y, Pan H, Qiu H, Chen S. Association of miRNA-499 rs3746444 A $>G$ variants with adenocarcinoma of esophagogastric junction (AEG) risk and lymph node status. Onco Targets Ther. 2019; 12:6245-6252.

47. Fattah SA, Ghattas MH, Saleh SM, Abo-Elmatty DM. Pre-micro RNA-499 Gene Polymorphism rs3746444 T/C is Associated with Susceptibility to Rheumatoid Arthritis in Egyptian Population. Indian J Clin Biochem. 2018; 33(1):96-101.

48. Ding W, Li M, Sun T, Han D, Guo X, Chen X, Wan Q, Zhang X, Wang J. A polymorphism rs3746444 within the pre-miR-499 alters the maturation of miR-499-5p and its antiapoptotic function. J CELL MOL MED. 2018; 22(11):5418-5428.

49. Wang D, Pan G. Association of rs2910164 Polymorphism in miRNA-146 and rs3746444 Polymorphism in miRNA-499 with Inflammatory Arthritis: A Meta-Analysis. BIOMED RES INT. 2019; 2019:7305750.

50. Qiu D, Han F, Zhuang H. MiR-499 rs3746444 polymorphism and hepatocellular carcinoma risk: A meta-analysis. J CANCER RES THER. 2018; 14(Supplement):S490-S493.

51. Chen W, Shao D, Gu H, Gong J, Zhang J. Hsa-mir-499 rs3746444 T/C Polymorphism is Associated with Increased Risk of Coronary Artery Disease in a Chinese Population. ACTA CARDIOL SIN. 2017; 33(1):34-40.

52. Fawzy MS, Toraih EA, Hamed EO, Hussein MH, Ismail HM. Association of MIR-499a expression and seed region variant (rs3746444) with cardiovascular disease in Egyptian patients. ACTA CARDIOL. 2018; 73(2):131-140.

53. Gholami M, Amoli MM. Comments on "Association between miR-499 rs3746444 polymorphism and coronary heart disease susceptibility: An evidence-based meta-analysis of 5063 cases and 4603 controls". GENE. 2019; 707:100-102.

54. Saleem M, Hodgkinson CP, Xiao L, Gimenez-Bastida JA, Rasmussen ML, Foss J, Payne AJ, Mirotsou M, Gama V, Dzau VJ et al. Sox6 as a new modulator of renin expression in the kidney. Am J Physiol Renal Physiol. 2020; 318(2):F285-F297.

55. Moher D, Liberati A, Tetzlaff J, Altman DG. Preferred reporting items for systematic reviews and meta-analyses: the PRISMA statement. BMJ. 2009; 339:b2535. 
56. Borenstein M, Hedges LV, Higgins JPT, Rothstein HR. A basic introduction to fixed-effect and randomeffects models for meta-analysis. RES SYNTH METHODS. 2010; 1(2):97-111.

57. Begg CB, Mazumdar M. Operating characteristics of a rank correlation test for publication bias. BIOMETRICS. 1994; 50(4):1088-1101.

58. Egger M, Davey SG, Schneider M, Minder C. Bias in meta-analysis detected by a simple, graphical test. BMJ. 1997; 315(7109):629-634.

59. Li K, Tie H, Hu N, Chen H, Yin X, Peng C, Wan J, Huang W. Association of two polymorphisms rs2910164 in miRNA-146a and rs3746444 in miRNA-499 with rheumatoid arthritis: a meta-analysis. HUM IMMUNOL. 2014; 75(7):602-608.

60. Stang A. Critical evaluation of the Newcastle-Ottawa scale for the assessment of the quality of nonrandomized studies in meta-analyses. EUR J EPIDEMIOL. 2010; 25(9):603-605.

\section{Tables}

Please see the supplementary files section to view the tables.

\section{Figures}




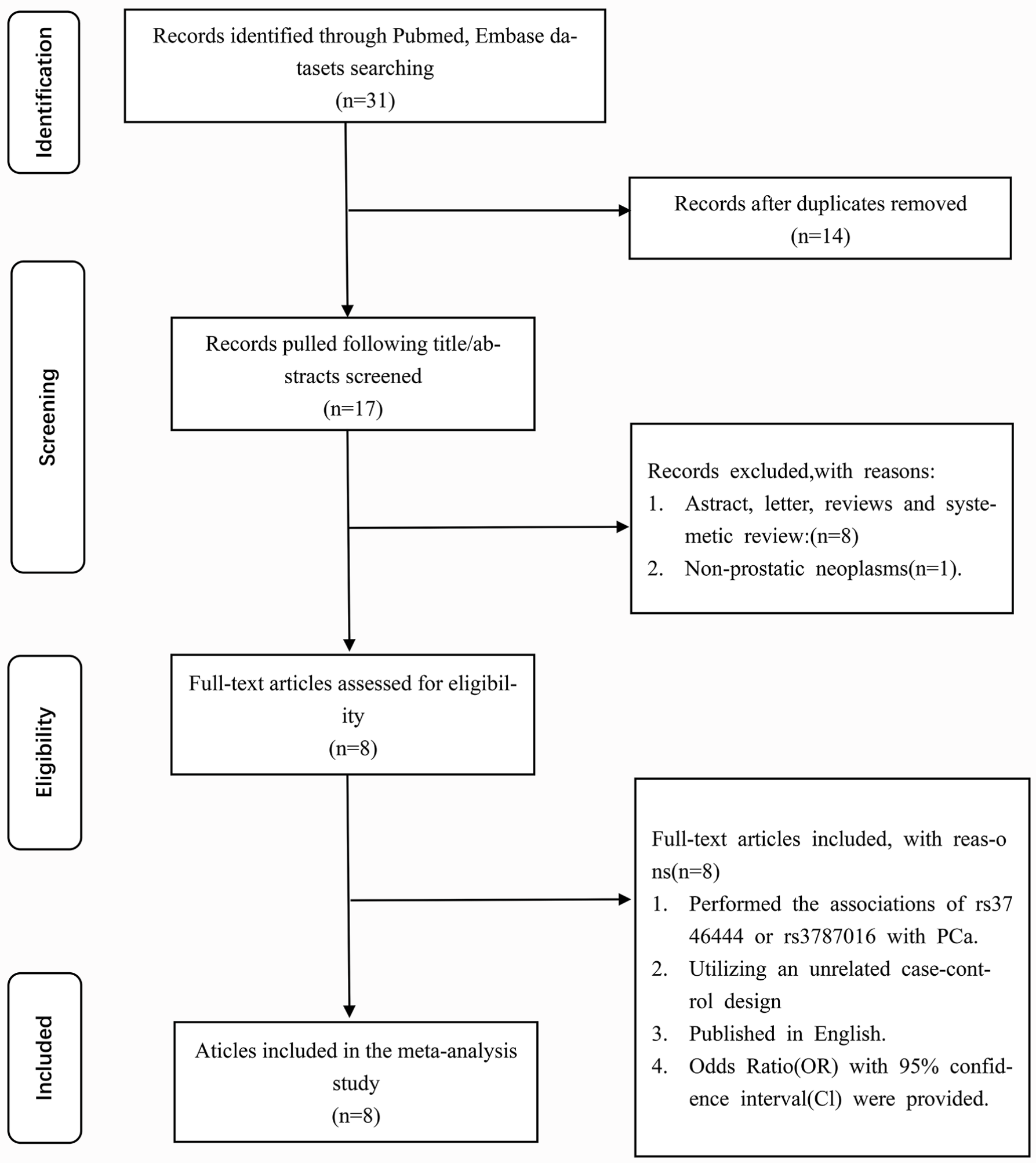

Figure 1

Flow diagram of systematic review of literature about association of rs3746444 /rs3787016 and Prostate Cancer 
ID

OR $(95 \% \mathrm{Cl})$

Weight

George (2011)

Nikolić (2015)

hashemi (2016)

Nouri (2019)

Overall (l-squared $=54.4 \%, p=0.087$ )

NOTE: Weights are from random effects analysis

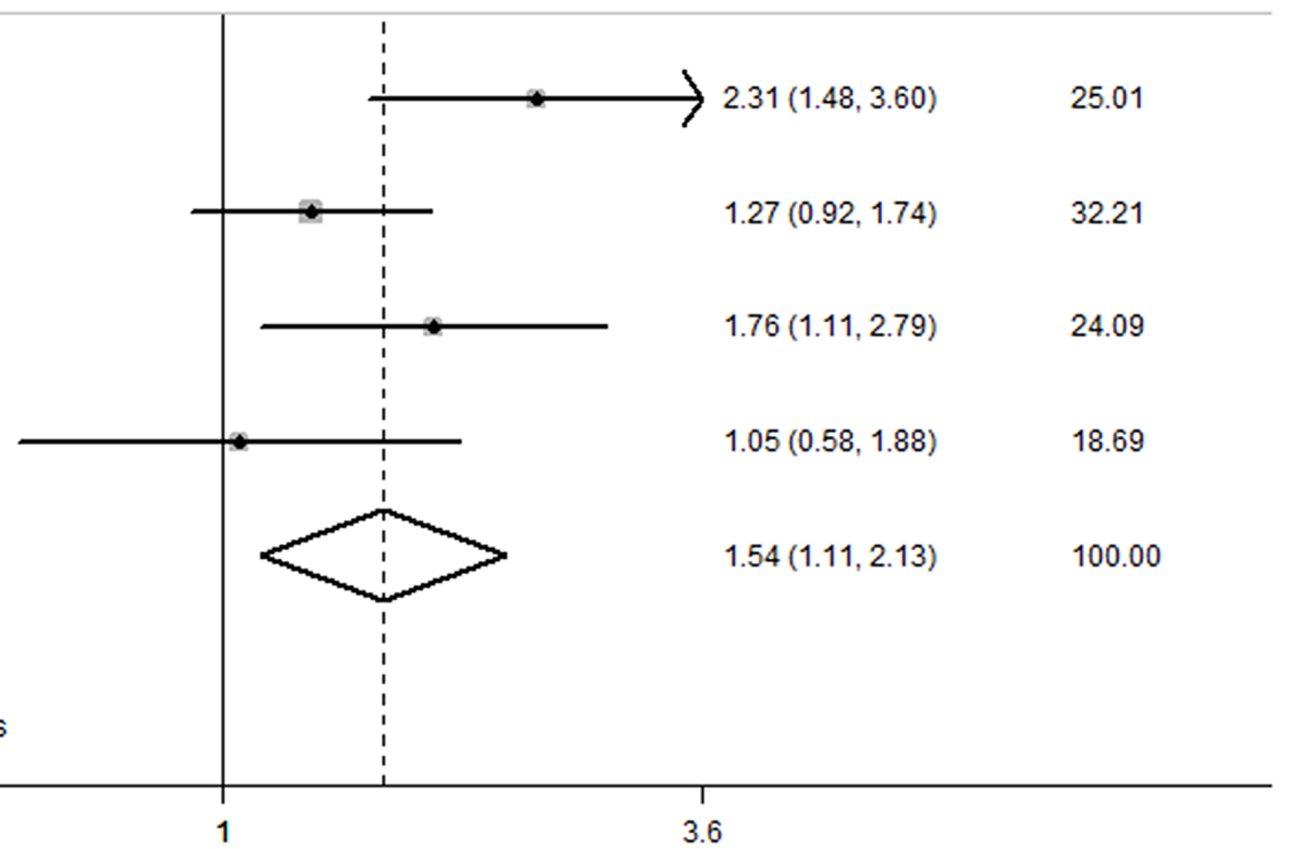

Figure 2

Forest plots of association between rs3746444 polymorphism in heterozygote allele model and PCa 
CGEMS study (2007)

JHH study (2009)

Replication study (2011)

Nikolić ZZ study (2013)

Cao DL study (2014)

Sattarifard (2018)

Overall (l-squared $=98.5 \%, p=0.000)$

NOTE: Weights are from random effects analysis
$1.14(0.99,1.30)$

17.10

$1.20(1.10,1.32)$

17.18

$1.21(1.04,1.41)$

17.06

$0.99(0.69,1.42)$

16.17

$\longrightarrow 11.81(9.29,15.01)$

16.75

$1.77(1.15,2.72)$

15.74

$1.80(1.01,3.20)$

100.00

\section{Figure 3}

Forest plots of association between rs3787016 polymorphism in allele model and PCa

a

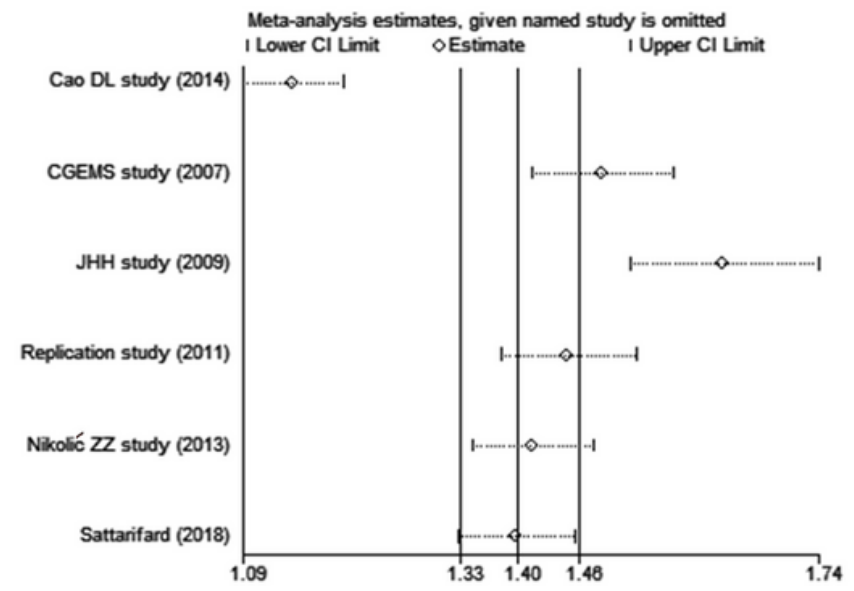

b

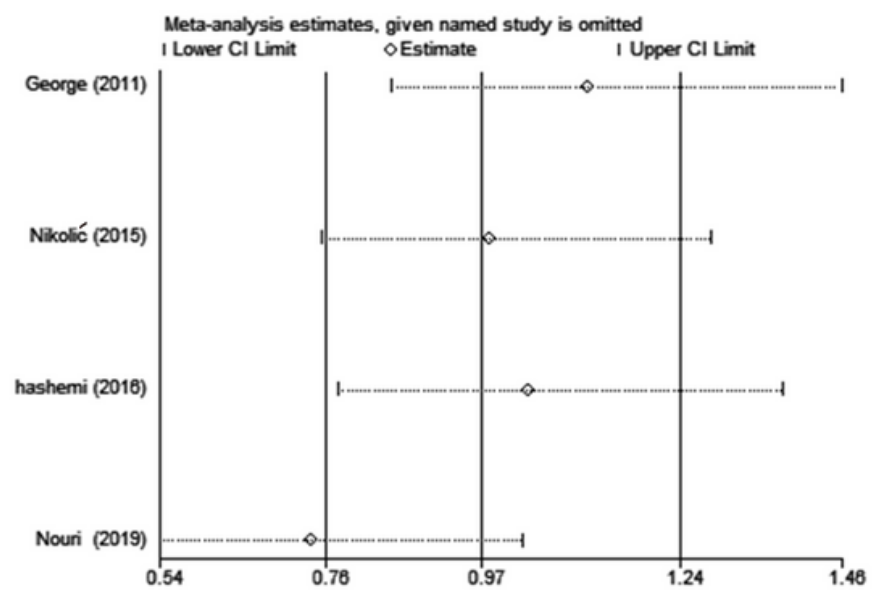

\section{Figure 4}

Sensitivity analysis for rs3787016 (a) and rs3746444 (b) 

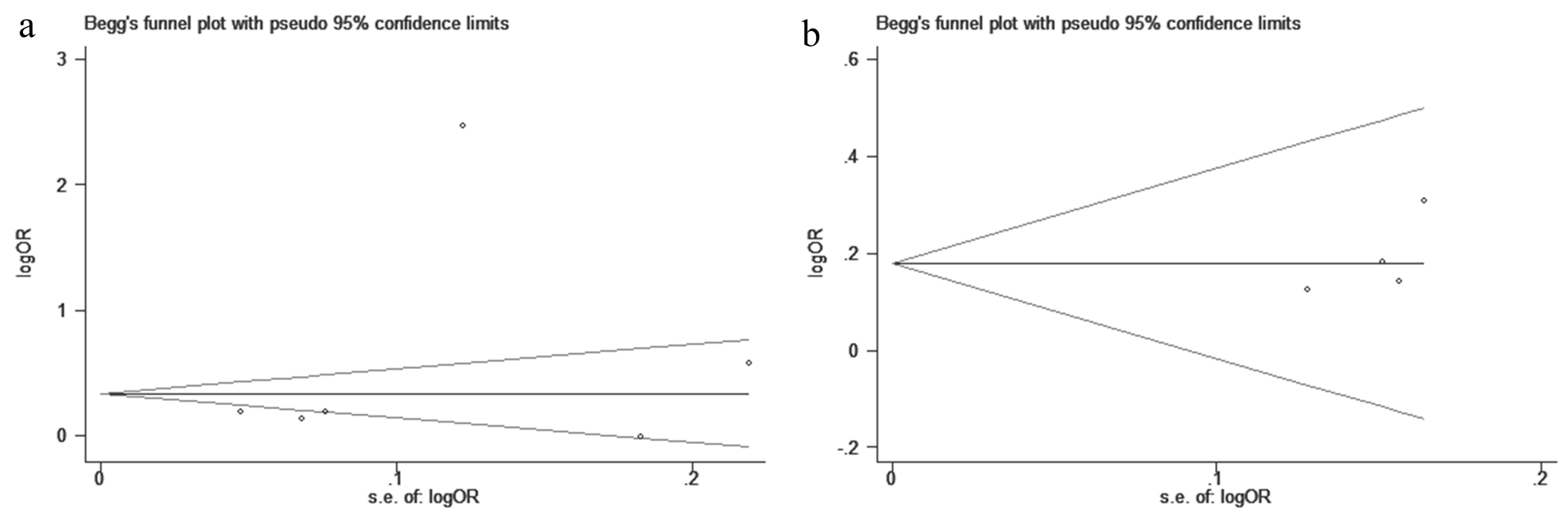

Figure 5

Begg's funnel plot of publication bias test for the allelic model of rs3746444 (a) and rs3787016 (b)

\begin{tabular}{|c|c|c|}
\hline \multicolumn{3}{|l|}{ PUBMED } \\
\hline \multicolumn{3}{|c|}{ Number:16 } \\
\hline $\begin{array}{l}((\text { rs3787016[Title/Abstract]) AND (Prostate Cancer[Title/Abstract])) } \\
\text { bstract]) AND (Prostate Cancer[Title/Abstract])) }\end{array}$ & \multicolumn{2}{|c|}{ OR ((rs3746444[Title/A } \\
\hline \multicolumn{3}{|l|}{ EMBASE } \\
\hline \multicolumn{3}{|l|}{ Number:15 } \\
\hline No. Query Results & Results & Date \\
\hline \#1. rs3746444:ab,ti AND 'prostate cancer':ab,ti & 8 & 4 Jun 2020 \\
\hline \#2. rs3787016:ab,ti AND 'prostate cancer':ab,ti & 7 & 4 Jun 2020 \\
\hline \#3. \#1 OR \#2 & 15 & 4 Jun 2020 \\
\hline
\end{tabular}

Figure 6

Search strategies in PUBMED and EMBASE 


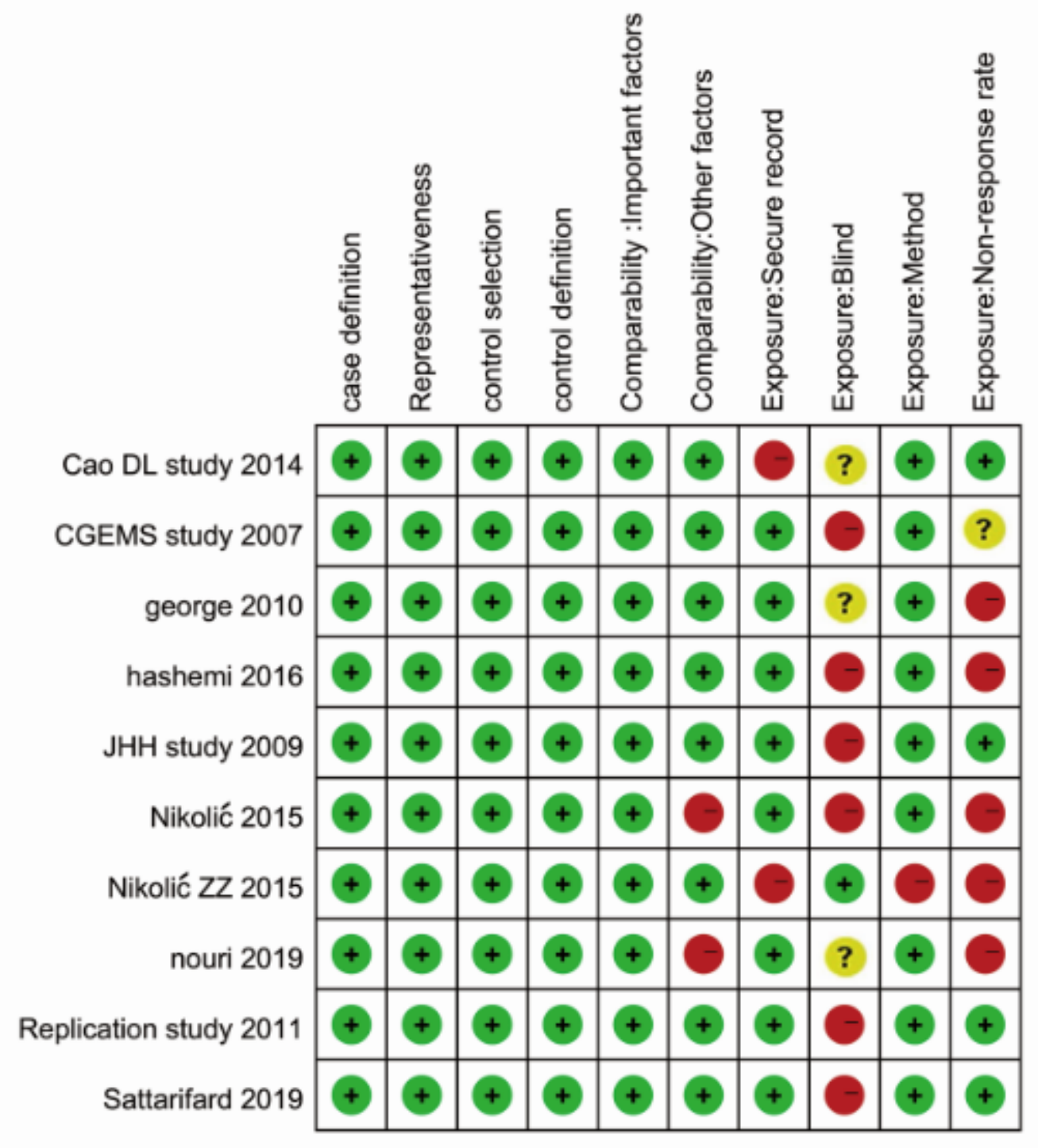

High

? Unclear

+ Low

Figure 7

Quality assessment of the included studies according to NOS

\section{Supplementary Files}

This is a list of supplementary files associated with this preprint. Click to download.

- Table1.tif

- Table2.tif

- FigureS1S3.docx 